\title{
EFFECT OF PROLONGED TREATMENT WITH BIOLOGICAL THERAPY IN PATIENTS WITH ULCERATIVE COLITIS WITH CONCOMITENT JOINT DAMAGE
}

DOI: 10.36740/WLek202104131

\author{
Antonina V. Varvarynets', Ivan V. Chopey', Ksenia I. Chubirko ${ }^{1}$, Artur V. Kurakh', ${ }^{1}$ Vasyl M. Voronych ${ }^{2}$, Yuriy P. Skrypynets ${ }^{2}$ \\ 'STATE HIGHER EDUCATIONAL INSTITUTION “UZHHOROD NATIONAL UNIVERSITY", UZHHOROD, UKRAINE \\ ${ }^{2}$ COMMUNAL NON-COMMERCIAL ENTERPRISE"UZHHOROD REGIONAL CLINICAL HOSPITAL OF UZHHOROD REGIONAL COUNCIL OF ZAKARPATTIA \\ REGION", UZHHOROD, UKRAINE
}

\begin{abstract}
The aim: Is to compare the effects of tofacitinib, adalimumab and budesonide clinical and laboratory signs of patients with moderate UC with concomitant articular syndrome. Materials and methods: 100 patients with moderately severe UC. Patients were divided into 2 groups. The I group consisted of patients with UC, which were treated with tofacitinib $10 \mathrm{mg}$ bid (TOF; $\mathrm{n}=28$ ). II group consisted of patients who were treated with adalimumab with a starting dose of $160 \mathrm{mg}$ and $80 \mathrm{mg}$ on the $2 \mathrm{nd}$ week of treatment, after which they received a subsequent dosage of $40 \mathrm{mg}$ per week ( $A D A ; n=32)$. Patients in the III group received budesonide $9 \mathrm{mg}$ qd (BUD; $n=40$ ).

Results: As a result of treatment in the TOF research group, leukocyte and CRP levels decreased compared to readings before treatment (from $13.6 \pm 2.4^{*} 10^{9} / \mathrm{l}$ and $169814.0 \pm 1.4$ $\mathrm{mg} / \mathrm{l}$ to $10.6 \pm 1.2^{*} 10^{\circ} / \mathrm{l}$ and $11.0 \pm 2.1 \mathrm{mg} / \mathrm{l}$ respectively, $\mathrm{p}<0.05$ ). Hemoglobin levels in this group slightly increased (from $104.2 \pm 9.2 \mathrm{~g} / \mathrm{l}$ to $126.1 \pm 10.2 \mathrm{~g} / \mathrm{l}, \mathrm{p}<0.05$ ). Among ADA patients, there was also an improvement in laboratory signs: leukocyte and CRP levels decreased (from $13.8 \pm 2.8^{*} 10^{9} / \mathrm{l}$ and $16.0 \pm 1.2 \mathrm{mg} / \mathrm{l}$ to $6.0 \pm 2.2^{*} 10^{9} / \mathrm{l}$ and $11.8 \pm 1.2$ $\mathrm{mg} / \mathrm{l}$ respectively, $\mathrm{r}<0.05$ ), hemoglobin increased (from $103.8 \pm 8.2 \mathrm{~g} / \mathrm{l}$ to $118.6 \pm 8.6 \mathrm{~g} / \mathrm{l} / \mathrm{l} \mathrm{r}<0.05$ ).

Conclusions: Tofacitinib and adalimumab in the treatment of patients with ulcerative colitis of moderate severity with concomitant joint damage showed a higher clinical and laboratory effectiveness compared to treatment with budesonide.
\end{abstract}

KEY WORDS: ulcerative colitis, articular syndrome, tofacitinib, adalimumab

Wiad Lek. 2021;74(4):977-980

\section{INTRODUCTION}

Ulcerative colitis (UC) - remains one of the most relevant problems of modern gastroenterology since its etiology is not fully understood. It clinically manifests as progressive inflammatory-necrotic lesions of the mucous membrane and submucous layer of the colon (local or diffuse) with the development of varying degrees of hemorrhages and ulcers. Characterized by periods of exacerbations and remission [1]

One of the most common extraintestinal complications of UC is joint damage. Peripheral arthritis occurs in 20$30 \%$ of UC patients, sacroiliitis - in 10-15\%, ankylosing spondylarthritis - in 3-4\%.

The most common form of joint lesion in patients with UC, is peripheral arthritis, which affects the hands, feet, elbows, wrists, knees. Pain can move from one joint to another. The activity of inflammation in the joints usually correlates with the degree of inflammation activity in the colon. Symptoms of peripheral arthritis usually disappear without causing long-term damage when the symptoms of $\mathrm{UC}$ are properly managed $[2,3]$.

Axial arthritis - is a form of arthritis also known as spondylitis or spondylarthritis, accompanied by pain in the lower back and sacroiliac joints. Notable is the fact, that pain can precede the appearance of intestinal symptoms of UC.

Sacroiliitis in UC is predominantly bilateral. Roentgenologic manifestations appear earlier than symptomatic manifestations of UC and have a different degree of severity, up to the ankylosis of sacroiliac joints.

Ankylosing spondylitis is a more severe form of arthritis. It usually develops in people with a genetic predisposition to bowel or urinary tract infections and tends to manifest before the age of 30 .

Diagnosis ofarthropathy in UC is carried out taking into account the following factors: the correlation between articular and intestinal manifestations; parallel occurrence of exacerbation of intestinal manifestations of UC and articular syndrome, predominant damage to large joints, asymmetry of articular syndrome; short-term articular manifestations; development of spondylitis and symmetrical sacroiliitis, especially in the carrier of the HLA-B27 gene; presence of X-ray signs. Laboratory markers of inflammation are also taken into account $[4,5]$.

Management of patients with UC and articular syndrome is based on the effective treatment of the underlying disease. The drugs of choice are 5 -amino acid group medications (mesalasine, mesacol, salofalk, etc.), which affect both intestinal 
Table I. Dynamics of indicatorsof complete blood count during treatment.

\begin{tabular}{|c|c|c|c|c|c|c|}
\hline \multirow[b]{2}{*}{ Indicator } & \multicolumn{2}{|c|}{$\begin{array}{r}\text { Study group } \\
(T O F, n=28)\end{array}$} & \multicolumn{2}{|c|}{$\begin{array}{l}\text { Study group } \\
(\text { ADA, } n=32)\end{array}$} & \multicolumn{2}{|c|}{$\begin{array}{l}\text { Study group } \\
\text { (BUD, } n=40 \text { ) }\end{array}$} \\
\hline & 1 week & 52 weeks & 1 week & 52 weeks & 1 week & 52 weeks \\
\hline Red blood cells, $10^{* 9} / /$ & $3,42 \pm 0,44$ & $4,72 \pm 0,22$ & $3,60 \pm 0,42$ & $4,64 \pm 0,22$ & $3,56 \pm 0,42$ & $4,42 \pm 0,14$ \\
\hline Leukocytes, $10 * 9 / 1$ & $13,60 \pm 2,42 * \#$ & $5,82 \pm 2,04$ & $13,82 \pm 2,81 * \#$ & $6,04 \pm 2,22$ & $14,02 \pm 2,34^{*} \#$ & $7,24 \pm 1,81$ \\
\hline Hemoglobin, g / I & $104,22 \pm 9,20^{*} \#$ & $126,14 \pm 10,24^{*} \#$ & $103,82 \pm 8,24^{*} \#$ & $118,60 \pm 8,62^{*} \#$ & $104,64 \pm 9,94^{*} \#$ & $116,24 \pm 7,12^{*} \#$ \\
\hline Hematocrit & $0,41 \pm 0,03$ & $0,43 \pm 0,02$ & $0,42 \pm 0,01$ & $0,43 \pm 0,03$ & $0,43 \pm 0,1$ & $0,41 \pm 0,1$ \\
\hline Platelets, $10^{9} / \mathrm{l}$ & $488,0 \pm 11,42$ & $327,12 \pm 10,10$ & $468,02 \pm 10,44$ & $386,04 \pm 12,62$ & $456,08 \pm 11,82$ & $398,02 \pm 11,04$ \\
\hline Lymphocytes, \% & $15,82 \pm 1,30$ & $24,04 \pm 1,72$ & $16,22 \pm 1,34$ & $23,80 \pm 1,72$ & $16,64 \pm 1,32$ & $24,20 \pm 1,20$ \\
\hline Neutrophils, \% & $68,64 \pm 4,22$ & $62,82 \pm 4,06$ & $64,62 \pm 4,02$ & $62,02 \pm 4,24$ & $62,44 \pm 4,04$ & $60,34 \pm 4,10$ \\
\hline Monocytes, \% & $4,20 \pm 0,14$ & $9,20 \pm 0,22$ & $4,06 \pm 0,12$ & $4,82 \pm 0,12$ & $4,74 \pm 0,10$ & $3,92 \pm 0,34$ \\
\hline Eosinophils, \% & $0,60 \pm 0,10$ & $3,72 \pm 0,90$ & $0,64 \pm 0,22$ & $2,64 \pm 0,20$ & $0,82 \pm 0,14$ & $1,12 \pm 0,12$ \\
\hline Basophils, \% & $0,32 \pm 0,04$ & $0,62 \pm 0,01$ & $0,32 \pm 0,04$ & $0,34 \pm 0,04$ & $0,64 \pm 0,12$ & $0,82 \pm 0,12$ \\
\hline Neutrophils abs., $10^{9} / \mathrm{l}$ & $9,60 \pm 0,90 * \#$ & $4,82 \pm 0,64$ & $9,24 \pm 0,40^{*} \#$ & $5,24 \pm 0,62$ & $8,88 \pm 0,22 * \#$ & $5,24 \pm 0,11$ \\
\hline Lymphocytes abs. $10^{9} / 1$ & $1,12 \pm 0,14$ & $2,44 \pm 0,92$ & $1,14 \pm 0,24$ & $1,86 \pm 0,12$ & $1,24 \pm 0,20$ & $1,14 \pm 0,12$ \\
\hline Monocytes abs., 109/l & $0,86 \pm 0,08$ & $0,84 \pm 0,08$ & $0,86 \pm 0,06$ & $0,84 \pm 0,02$ & $0,88 \pm 0,02$ & $0,84 \pm 0,02$ \\
\hline Eosinophils abs, $.10^{9} / \mathrm{l}$ & $0,24 \pm 0,02$ & $0,18 \pm 0,04$ & $0,24 \pm 0,02$ & $0,24 \pm 0,02$ & $0,32 \pm 0,08$ & $0,12 \pm 0,04$ \\
\hline Basophiles abs., $10^{9} / \mathrm{I}$ & $0,04 \pm 0,01$ & $0,02 \pm 0,01$ & $0,04 \pm 0,02$ & $0,04 \pm 0,02$ & $0,04 \pm 0,02$ & $0,02 \pm 0,01$ \\
\hline Reticulocytes, \% & $1,82 \pm 0,90$ & $1,62 \pm 0,22$ & $1,94 \pm 0,44$ & $1,64 \pm 0,92$ & $1,94 \pm 0,12$ & $1,76 \pm 0,42$ \\
\hline CRP, mg/l & $14,0 \pm 1,4^{*} \#$ & $11,0 \pm 2,1 * \#$ & $16,0 \pm 1,2^{*} \#$ & $11,8 \pm 1,2^{*} \#$ & $14,2 \pm 0,2$ & $12,2 \pm 0,9$ \\
\hline
\end{tabular}

* - the difference is statistically probable when comparing indicators before and after treatment, $\mathrm{p}<0.05$.

$\#$ - the difference is statistically probable when compared to the control group, $p<0.05$.

Table II. VAS index before and after treatment.

\begin{tabular}{cccc}
\hline VAS index cm & TOF & ADA & BUD \\
\hline Before treatment & $8.6 \pm 0.2 \mathrm{~cm}^{*} \#$ & $8.5 \pm 0.2 \mathrm{~cm}^{*} \#$ & $8.4 \pm 0.3 \mathrm{~cm}^{*} \#$ \\
\hline 52 weeks & $8.6 \pm 0.2 \mathrm{~cm}^{*} \#$ & $8.5 \pm 0.2 \mathrm{~cm}^{*} \#$ & $8.6 \pm 0.2 \mathrm{~cm}^{*} \#$ \\
\hline
\end{tabular}

* - the difference is statistically probable when comparing indicators before and after treatment, $p<0.05$.

\# - the difference is statistically probable when compared to the control group, $p<0.05$.

and articular symptoms. In case of significant refractoriness to these drugs, glucocorticoids are prescribed additionally [6].

In severe forms of UC, immunosuppressants (cyclosporin, azathioprin and metottrexate) are also used.

In recent years, the number of severe forms of UC has increased dramatically, and anti-TNF drugs (adalimumab) and Janus-kinase inhibitors (tofacitinib) have been added to treatment regimens $[7,8]$.

\section{THE AIM}

The aim of the study is to compare the effects of tofacitinib, adalimumab and budesonide on clinical and laboratory signs of patients with moderate UC with concomitant articular syndrome.

\section{MATERIALS AND METHODS}

The study was conducted in Uzhhorod Regional Clinical Hospital of Uzhhorod Regional Council of the Transcarpathian Regionfrom 2017 to 2018.100 patients with moderately severe
UC aged between 18 and 75 years old were included in the study. The average age of patients was $39.2 \pm 12.6$. At the time of inclusion in the study, the disease duration was not less than 6 months. The activity of the disease was determined by the clinical and endoscopic activity index. Patients were divided into 2 groups. The I group consisted of patients with UC, which were treated with tofacitinib $10 \mathrm{mg}$ bid (TOF; $\mathrm{n}=28$ ). II group consisted of patients who were treated with adalimumab with a starting dose of $160 \mathrm{mg}$ and $80 \mathrm{mg}$ on the 2nd week of treatment, after which they received a subsequent dosage of $40 \mathrm{mg}$ per week (ADA; $\mathrm{n}=32$ ). Patients in the III group received budesonide 9mg qd (BUD; $\mathrm{n}=40$ ).

Examination of patients with complaints of joint pain included: physical examination conducted by counting swollen and painful joints. The intensity of arthralgia was determined using the visual-analog scale (VS), which is a line of $10 \mathrm{~cm}$ long, where the mark 0 corresponds to the value of "pain is absent", $10 \mathrm{~cm}$ - "maximum pain". To assess the severity of pain, the patient is offered to put a mark on the scale, which corresponds to the intensity of pain.

Also, laboratory signs were evaluated during treatment. 


\section{RESULTS}

The study lasted 52 weeks. At the beginning of the study, all patients had a slight decrease in hemoglobin levels, which can be explained by the presence of chronic bleeding. There was also an increase in leukocyte levels and CRP in the blood, which indicates the presence of an inflammatory process.

When evaluating the clinical response in all groups at the end of treatment, in the TOF research group, leukocyte and $\mathrm{CRP}$ indicators decreased compared to similar indicators before treatment (from $13.6 \pm 2.4^{*} 10^{9} / 1$ and $14.0 \pm 1.4 \mathrm{mg} / \mathrm{l}$ to $10.6 \pm 1.2^{\star} 10^{9} / \mathrm{L}$ and $11.0 \pm 2.1 \mathrm{mg} / \mathrm{l}$ respectively, $\mathrm{r}<0.05$ ). Hemoglobin levels in this group slightly increased (from $104.2 \pm 9.2 \mathrm{~g} / \mathrm{l}$ to $126.1 \pm 10.2 \mathrm{~g} / \mathrm{l}, \mathrm{p}<0.05)$. Among ADA patients, there was also an improvement in laboratory signs: leukocyte and CRP levels decreased (from $13.8 \pm 2.8^{\star} 10^{9} / 1$ and $16.0 \pm 1.2 \mathrm{mg} / \mathrm{l}$ to $6.0 \pm 2.2^{\star} 10^{9} / \mathrm{l}$ and $11.8 \pm 1.2 \mathrm{mg} / \mathrm{l} \mathrm{re}-$ spectively, $\mathrm{r}<0.05$ ), hemoglobin increased (from 103.8 \pm 8.2 $\mathrm{g} / \mathrm{l}$ to $118.6 \pm 8.6 \mathrm{~g} / \mathrm{l} / \mathrm{l} \mathrm{r}<0.05)$.

In patients receiving budesonide, statistically significant changes in laboratory signs were not observed. (Table I).

Joint lesions were seen in a significant number of patients in all groups. In the TOF group, $11(39,2 \%)$ patients had arthropathies, which included peripheral arthritis $-6(21,4 \%)$, sacroiliitis - 3(10,7\%), AS - $2(7,14 \%)$ patients. In the ADA group, joint damage was observed in $12(37.5 \%)$ patients, including peripheral arthritis - in $6(18.75 \%)$, sacroiliitis - in $4(12.5 \%), \mathrm{AC}-$ in $2(6.25 \%)$ patients. In the BUD group, joint damage was noted in $15(37.5 \%)$ patients, including peripheral arthritis - 7 (17.5\%), sacroiliitis - in $5(12.5 \%)$, $\mathrm{AC}-3(7.5 \%)$ patients. At the beginning of treatment, there was no statistically significant difference in the degree of pain between all of the studied groups $(8.6 \pm 0.2 \mathrm{~cm}, 8.5 \pm 0.2 \mathrm{~cm}$ and $8.4 \pm 0.3 \mathrm{~cm}$ on the VAS scale in the TOF, ADA and BUD groups, respectively, $\mathrm{p}>0.05$ ). (Table II).

\section{DISCUSSION}

In this study, we investigated the changes in clinical and laboratory signs of patients with moderately severe UC when treated with budesonide, adalimumab and tofacitinib. Gathered data enables us to better understand the course of the disease and to monitor the safety of management of ulcerative colitis with these drugs.

When comparing the study indicators between patients of the study and control groups, it was found that in the tofacitinib and adalimumab group, the leukocyte values and CRP were statistically lower, and hemoglobin was higher, compared to the budesonide group. These findings correlate with results of previous studies, which were considered during UC management planning $[8,9,10]$.

After treatment in the TOF research group, the VAS index decreased compared to the similar indicator before treatment (from $8.6 \pm 0.2 \mathrm{~cm}$ to $5.6 \pm 0.3 \mathrm{~cm}, \mathrm{p}<0.05$ ). In the ADA group, a decrease in this indicator compared to the same treatment was also observed (from $8.5 \pm 0.2 \mathrm{~cm}$ to $6.2 \pm 0.2 \mathrm{~cm}, \mathrm{p}<0.05$ ). In the BUD group there were no statistically probable changes in the degree of pain. At the same time, the severity of pain on the VAS scale after treatment between patients in the group of tofacitinib and adalimumab was statistically lower compared to same values in the budesonide group.Similar results were seen in other published research $[11,12]$.

Tofacitinib and adalimumab provide a better therapeutic effect in patients with moderate ulcerative colitis and articular syndrome, when compared to budesonide. Further research is needed to study the financial aspects of patient management with drugs that were mentioned above.

\section{CONCLUSIONS}

Tofacitinib and adalimumab in the treatment of patients with ulcerative colitis of moderate severity with concomitant joint damage showed a higher clinical and laboratory effectiveness compared to treatment with budesonide. Further research is needed, in particular on the study of pharmaco-economic aspects of the use of these drugs.

\section{REFERENCES}

1. Feuerstein J., Cheifetz A. Ulcerative colitis: epidemiology, diagnosis, and management MayoClin Proc. 2014; 89(11):1553-1563.

2. Vavricka S., Rogler G., Gantenbein C. et al. Chronological Order of Appearance of Extraintestinal Manifestations Relative tothe Time of IBD Diagnosis in the Swiss Inflammatory Bowel Disease Cohort.Inflamm Bowel Dis. 2015;21(8):1794-1800.

3. Harbord M., Annesse V., Vavricka S. et al .The First European Evidencebased Consensus on Extra-intestinal Manifestationsin Inflammatory Bowel Diseas. Journal of Crohn's and Colitis. 2015;10(3):239-254.

4. Sieper J. Poddubnyy D. Axial spondyloarthritis.Lancet. 2017:390 (10089);73-84.

5. Pouillon L., Bossuyt P., Vanderstukken J. et al. Management of patients with inflammatory bowel disease and spondyloarthritis. Expert Review Of Clinical Pharmacology. 2017:10(12);1363-1374.

6. Panés J., Vermeire S., Lindsay J. et al. Crohns Colitis. Tofacitinib in Patients with Ulcerative Colitis: Health-Related Quality of Life in Phase 3 Randomised Controlled Induction and Maintenance Studies.2018;24;12(2):145-156.

7. Izzo R., Bevivino G., Monteleone G. Tofacitinib for the treatment of ulcerative colitis.Expert OpinInvestig Drugs. 2016;25(8):991-7. doi: 10.1080/13543784.2016.1189900.

8. Izzo R., Bevivino G., Monteleone G. Tofacitinib for the treatment of ulcerative colitis.Expert OpinInvestig Drugs. 2016;25(8):991-7. doi: 10.1080/13543784.2016.1189900.

9. Taxonera C., Iglesias E., Munoz F. et al. Adalimumab maintrance treatment in ulcerative colitis: outcomes by prior anti-TNF use and efficacy of dose escalation. Dig Dis Sci. 2017;62:481-90.

10. Balint A., Farkas K., Palatka K. et al. Efficacy and safety of adalimumab in ulcerative colitis refractory to conventional therapy in routine clinical practice. J Crohns Colitis. 2016;10:26-30.

11. Botteman M.F., Hay J.W., Luo M.P. et al. Cost effectiveness of adalimumab for the treatment of ankylosing sponditis in the United Kingdom. Rheumatology. 2007;46:1320-1328.

12. Van der Heijde D., Deodnar A., Wei J.C. et al. Tofacitinib in patients with ankylosing spondylitis: a phase 2, 16-week, randomized, placebocontrolled, dose-ranging study. Ann Rheum Dis. 2017. doi:10.1136 annrheumdis-20160210322. 


\section{ORCID and contributionship:}

Antonina V. Varvarynets: 0000-0001-5859-1040 A,DF

Ivan V. Chopey: 0000-0003-4626-0855 ${ }^{A, F}$

Ksenija I. Chubirko: 0000-0002-4379-0538 ${ }^{A, B}$

Artur V. Kurakh: 0000-0003-2793-5044 E,C

Vasyl M. Voronych: 0000-0001-9718-3496 $6^{A, B}$

Yuriy P. Skrypynets: $0000000297414175^{B, C}$

\section{Conflict of interest:}

The Authors declare no conflict of interest.

\section{CORRESPONDING AUTHOR}

Antonina V. Varvarynets

Uzhhorod national university

71 Minayska St., 88000 Uzhhorod, Ukraine

tel: +380679810601

e-mail: tonichka8387@gmail.com

Received: 26.10 .2020

Accepted: 03.03.2021

A - Work concept and design, B - Data collection and analysis, C - Responsibility for statistical analysis,

$\mathbf{D}$-Writing the article, $\mathbf{E}$-Critical review, $\mathbf{F}$ - Final approval of the article 